\title{
Investigating social media statistics of usage and its determinant factors in students of Kurdistan University of Medical Sciences in 2018: A cross-sectional study.
}

\section{Hiva Bozorgpanah}

Research Committee, Kurdistan University of Medical Sciences, Sanandaj, Iran

\section{Ghobad Moradi}

Social Determinants of Health Research Center, Research Institute for Health Development, Kurdistan

University of Medical Sciences, Sanandaj, Iran

Pourya Bahrami ( $\triangle$ Pouryabahrami78@gmail.com )

Research Committee, Kurdistan University of Medical Sciences, Sanandaj, Iran

\section{Elham Noori}

Research Committee, Kurdistan University of Medical Sciences, Sanandaj, Iran

\section{Mohammad Pourya Ezati}

Research Committee, Kurdistan University of Medical Sciences, Sanandaj, Iran

\section{Nazanine Soleimani}

Research Committee, Shahid Sadoughi University of Medical Sciences, Yazd, Iran

\section{Fayegh Yousefi}

Neuroscience Research Center, Health Development Research Institute, Kurdistan University of Medical

Sciences, Sanandaj, Iran

\section{Research Article}

Keywords: Social Media, Students, Usage Pattern, Prevalence

Posted Date: March 15th, 2021

DOl: https://doi.org/10.21203/rs.3.rs-257862/v1

License: (c) (i) This work is licensed under a Creative Commons Attribution 4.0 International License. Read Full License 


\section{Abstract}

Background and Aim: the present study was conducted to investigate social media statistics of usage and its determinant factors in students of Kurdistan University of Medical Sciences in 2018.

Materials and Methods: This study is a cross-sectional-analytical study. The total of 380 students of Kurdistan University of Medical Sciences were randomly selected by Probability Proportional to Size Sampling method, from the lists of the students in each faculty. The data collection tool was a researcher-made questionnaire, organized in four sections. Data analysis was done using descriptive and inferential statistics by SPSS software version 21.

Results: Based on the results of this study $373(98.2 \%)$ of the sample students were on social media, which the most popular ones among them were Telegram (94.1\%), Instagram (78.8\%) and Whatsapp (61.9\%), respectively. The average time spent on social media among students was reported to be 2.78 hours per day and is a significant difference between age groups in terms of attitudes toward using social media $(P=0.031)$.

Conclusion: the results of this study suggested that the majority of students use social media. Since improper use of social media can exert unfortunate effects on different aspects of life of students, and negatively influence their education.

\section{Introduction}

Internet is a multipurpose tool used for engaging in social communication, recovery of large amounts of information and doing leisure activities (1).Social media as a subcategory of internet, with different levels of access, is created for the purpose of interpersonal communication (2).

Statistics suggest that, the number of social media users has doubled from 2008 to 2010 (3). Facebook, Telegram and Instagram are among the most popular social media platforms (4).According to recent studies, Telegram is the most popular platform in Iran (5). In Korea $99.9 \%$ of adolescents use Internet in their daily life(6). The internet usage among U.S. adolescents has increased from $89.4 \%$ in 2014 to $97.5 \%$ in 2016 (7). Following the same pattern, the adolescent Internet usage rate in Iran has increased from 3.8\% in 2000 to more than $68.5 \%$ in 2016(8).

Excessive use of social media can lead to several undesirable effects, including: anxiety, stress and adverse effects on school performance(9). Internet addiction can also be associated with psychological problems such as depression and drug abuse, suicide and nomophobia $(10,11)$. Reasons for such interest in using Internet is due to its easy access, widespread use, low cost, multimedia sharing feature and lack of need for special skills (12). According to several studies conducted in Iran, since students are often away from their families after admission to the University, in order to stay in touch with their friends and families, students tend to use social media which makes the effects of social media perfectly visible in this period(13). According to a study by Dastani et al. (2015) in Gonabad University of Medical Sciences, the main purpose of social media usage in students are communication with old friends, finding new friends and entertainment (14). According to a study by Pouralajel et al., The higher the use of the Internet, the lower the students' grades, and in addition, better students' grades, was associated with less social media use (10). 
Considering the widespread use of social media and its associated complications, the present study aims to investigate the social media usage pattern in Kurdistan University of Medical Sciences in 2018.

\section{Materials And Methods}

Participants and Setting: The present study is a cross-sectional-analytical study, which was conducted on students of Kurdistan University of Medical Sciences in 2018. The sample was consisted of 380 students from faculties of medicine, dentistry, nursery and midwifery, paramedics and health sciences, which were randomly selected by Probability Proportional to Size Sampling method from the list of the students in each faculty.

Data Collection: The data collection tool was a questionnaire designed by researchers that was completed by each participant and then collected and analysed. The content validity of the questionnaire was evaluated through a panel of experts. Also Cronbach's alpha coefficient was used in order to obtain its reliability. To calculate the Cronbach's alpha coefficient, 30 questionnaires were completed by students who had the inclusion criteria. The value of alpha was 0.83 . The questionnaire was organized in 4 sections. The first section included demographic information, the second section included questions regarding social media membership history, the third section included the quantitative and qualitative evaluations of social media usage and the last section for students who had account in social media that included questions regarding attitude assessment. The questionnaires were distributed and were provided to the participants after obtaining their consent.

Data Analysis: In this study relationship between time spent on social media and school of study was investigated between students of medicine, dentistry, nursery and midwifery, paramedical sciences and health sciences schools. Also for investigation relationship between the most important reasons for using social media and school of study and field of study sample was divided into medicine school students and other schools students. SPSS software version 21 was used to enter the data. Central tendency, dispersion indices and ratio were used to describe the variables using tables and graphs (frequency and percentage). One-way analysis of variance, chi square,T-test and goodness of fit test of chi-square was used for analytical analysis. A significance level of $5 \%$ was considered.

Ethical approval: This study was approved by the Ethics Committee and Research Council of Kurdistan University of Medical Sciences. The questionnaire was distributed between students after inform them about our study goals and take the students informed consent to participate in our study. Students could refuse to answer our questionnaire. All clause of Declaration of Helsinki were done. Data was accessible only to the researchers and individual respondents.

\section{Results}

380 students were studied in terms of social media status in this cross-sectional study. 168 (44.2\%) of the students were male and $212(55.8 \%)$ of them were female. Most of the participants were single (86.3\%), and less than 25 years old (81.8\%). 373 of the sample students (98.2\%) were on social media and 7 of them (1.8\%) did not have any social media accounts. The three most popular social media platforms were Telegram (94.1\%), Instagram (78.8\%) and Whatsapp (61.9\%), respectively]Table 1[. Most (83.9\%) of the students who were on social media stated that they have been on social media for more than 2 years. 
Table 1. Frequency of membership in social media, personal account and total time spent on social media in participants.

\begin{tabular}{|c|c|c|}
\hline Variable & & Frequency (Percent) \\
\hline \multirow[t]{2}{*}{ Membership on social media } & Yes & $373(98.2 \%)$ \\
\hline & No & $7(1.8 \%)$ \\
\hline \multirow[b]{2}{*}{ The reason for not being on social media } & Not familiar & $4(57.1 \%)$ \\
\hline & Not interested & $3(42.9 \%)$ \\
\hline \multirow{11}{*}{$\begin{array}{l}\text { on which social media platforms they have } \\
\text { account }\end{array}$} & Telegram & $351(94.1 \%)$ \\
\hline & Instagram & $294(78.8 \%)$ \\
\hline & WhatsApp & $231(61.9 \%)$ \\
\hline & Facebook & $128(33.7 \%)$ \\
\hline & Viber & $114(30.6 \%)$ \\
\hline & Imo & $110(29.5 \%)$ \\
\hline & Line & $84(22.5 \%)$ \\
\hline & YouTube & $70(18.8 \%)$ \\
\hline & Twitter & $61(16.4 \%)$ \\
\hline & Google & $56(15 \%)$ \\
\hline & Tango & $43(11 \%)$ \\
\hline \multirow{6}{*}{ Total time spent on social media per day } & 1 hour & $73(19.6 \%)$ \\
\hline & 2 hours & $109(29.3 \%)$ \\
\hline & 3 hours & $88(23.7 \%)$ \\
\hline & 4 hours & $51(13.7 \%)$ \\
\hline & 5 hours & $31(8.3 \%)$ \\
\hline & More than 6 hours & $20(5.4 \%)$ \\
\hline
\end{tabular}

The duration of membership in social media in female students is longer than male students. Among those who were aware of social media platforms and had membership, 294 (77.8\%) became familiar through friends, 18 (4.8\%) through the press, 61 (16.3\%) through websites, 18 (4.8\%) through television, 55 (14.7\%) through university's ambience and 48 (12.9\%) through factors other than the ones mentioned. The average time spent on social media among the studied population is $2.78( \pm 1.41)$ hours per day. There is a significant difference in time spent on social media among male and female students $(p=0.041)$, the average time spent online among 
girls is higher than boys. In other cases, there is no significant difference between the time spent online considering the students' school of study $(P=0.053)$ and Grade $(P=0.588)$ ]Table 2[.

Table 2. The relationship between time spent on social media and sex, school of study and grade

\begin{tabular}{|c|c|c|c|}
\hline Variable & Frequency (Percent) & $\begin{array}{l}\text { Mean } \\
\text { (Standard Deviation) }\end{array}$ & $P$ value \\
\hline \multicolumn{4}{|l|}{ Sex } \\
\hline Male & $161(44.2 \%)$ & $2.61(1.28)$ & \multirow{2}{*}{0.041} \\
\hline Female & $211(55.8 \%)$ & $2.91(1.49)$ & \\
\hline \multicolumn{4}{|l|}{ Grade } \\
\hline Associate and Bachelor & $200(52.6 \%)$ & $2.74(1.43)$ & \multirow[t]{3}{*}{0.588} \\
\hline Masters & $14(3.7 \%)$ & $2.50(1.69)$ & \\
\hline $\mathrm{PhD}$ & $166(43.7 \%)$ & $2.85(1.37)$ & \\
\hline \multicolumn{3}{|l|}{ School of study } & \multirow{6}{*}{0.053} \\
\hline Medicine & $137(36.1 \%)$ & $2.69(1.37)$ & \\
\hline Dentistry & $41(10.8 \%)$ & $3.25(1.43)$ & \\
\hline Nursery and Midwifery & $82(21.6 \%)$ & $2.70(1.38)$ & \\
\hline Paramedical sciences & $70(18.4 \%)$ & $3(1.55)$ & \\
\hline Health sciences & $50(13.2 \%)$ & $2.47(1.26)$ & \\
\hline
\end{tabular}

A total of 229 students $(61.4 \%)$ of those who were on social media have stated that they do not accept friendship requests from strangers, $112(30 \%)$ sometimes accept and 32 (8.6\%) accept strangers' requests. 348 (93.8\%) of the students stated that their parents were aware of their membership in social media. 164 (44.1\%) of the students stated that their face to face communication has decreased due to social media. Also 321 (86.5\%) of the students agreed to the importance of social media. A significant relationship was observed between school of study and information acquisition, entertainment. [Table 3].

Table 3. Relationship between the most important reasons for using social media and school of study, field of study and gender variables 


\begin{tabular}{|c|c|c|c|c|c|c|c|}
\hline \multicolumn{2}{|l|}{ Variable } & $\begin{array}{l}\text { Information } \\
\text { acquisition }\end{array}$ & P-value & Entertainment & P-value & $\begin{array}{l}\text { Image and } \\
\text { video }\end{array}$ & P-value \\
\hline & & $\begin{array}{l}\text { [Frequency } \\
\text { (Percent)] }\end{array}$ & & $\begin{array}{l}\text { [Frequency } \\
\text { (Percent)] }\end{array}$ & & $\begin{array}{l}\text { [Frequency } \\
\text { (Percent)] }\end{array}$ & \\
\hline \multirow{3}{*}{$\begin{array}{c}\text { School } \\
\text { of } \\
\text { study }\end{array}$} & Medicine & 103)39.6( & 0.051 & $76(42.9)$ & $\mathrm{P}<0.001$ & $48(44.9)$ & \multirow{3}{*}{0.07} \\
\hline & & & & & & & \\
\hline & Other & $157(60.4)$ & & $101(57.1)$ & & $107(55.1)$ & \\
\hline \multirow{2}{*}{$\begin{array}{r}\text { Field of } \\
\text { study }\end{array}$} & Medicine & $94(36.2)$ & \multirow[t]{2}{*}{0.001} & $73(41.2)$ & \multirow[t]{2}{*}{0.002} & $43(40.2)$ & \multirow[t]{2}{*}{0.018} \\
\hline & other & 166 (63.8) & & 104 (58.8) & & 64 (59.8) & \\
\hline \multirow{2}{*}{ Sex } & Female & $109(41.9)$ & \multirow[t]{2}{*}{0.218} & $72(40.7)$ & \multirow[t]{2}{*}{0.180} & $47(43.9)$ & \multirow[t]{2}{*}{0.497} \\
\hline & Male & $151(58.1)$ & & 105 (59.3) & & $60(56.1)$ & \\
\hline
\end{tabular}

According to the results of one-way analysis of variance test, it can be concluded that there is no significant difference between the attitudes of students with different levels of education $(P=0.413)$. Also, there is no significant difference between different fields of study in terms of attitudes toward using social media $(P=$ 0.176), but there is a significant difference between age groups in terms of attitudes toward using social media $(P=0.031)$. Of the 373 students who had accounts in the social media, 372 students responded to the attitude questionnaire, the evaluation of which $75 \%$ of students $75 \%$ of students said that if they had free time, they would spend their time in social media, which was very different from those who disagreed with this attitude. $76.9 \%$ of students said visiting social media is part of their schedule. $72.8 \%$ of students believed that on social media, users are less likely to declare their personality and identity correctly and more likely to use nicknames and characters; Because they do not have the necessary confidence in this environment to tell the truth $(P<$ $0.001)$ ] Table 4 placed at the end of the document [.

Table 4. Students attitude about social media 


\begin{tabular}{|c|c|c|c|c|c|}
\hline de assessment & $\begin{array}{l}\text { I totally } \\
\quad \text { agree } \\
\text { And } \\
\text { I agree } \\
\mathrm{N}(\%)\end{array}$ & $\begin{array}{l}\text { No idea } \\
\text { N (\%) }\end{array}$ & $\begin{array}{l}\text { I totally } \\
\quad \text { disagree } \\
\text { And } \\
\text { I disagree } \\
\text { N (\%) }\end{array}$ & $\begin{array}{l}\text { Goodness } \\
\text { of fit test } \\
\text { of chi- } \\
\text { square }\end{array}$ & p-value \\
\hline $\begin{array}{l}\text { se social media to learn } \\
\text { snce }\end{array}$ & $331(89 \%)$ & 29 (7.8\%) & $12(3.2 \%)$ & 519.500 & $\mathrm{P}<0.001$ \\
\hline $\begin{array}{l}\text { ial media have a good level } \\
\text { ecurity }\end{array}$ & $\begin{array}{l}111 \\
(29.8 \%)\end{array}$ & $\begin{array}{l}126 \\
(33.9 \%)\end{array}$ & $\begin{array}{l}135 \\
(36.3 \%)\end{array}$ & 2.371 & 0.306 \\
\hline $\begin{array}{l}\text { or one day I do not check } \\
\text { social media, I will get } \\
\text { strated }\end{array}$ & $\begin{array}{l}199 \\
(53.5 \%)\end{array}$ & $56(15.1 \%)$ & $\begin{array}{l}117 \\
(31.5 \%)\end{array}$ & 83.048 & $\mathrm{P}<0.001$ \\
\hline $\begin{array}{l}\text { tead of having fun } \\
\text { doors, I like to be on social } \\
\text { lia }\end{array}$ & $68(18.3 \%)$ & $63(16.9 \%)$ & $\begin{array}{l}241 \\
(64.8 \%)\end{array}$ & 165.694 & $\mathrm{P}<0.001$ \\
\hline $\begin{array}{l}\text { en I have an issue in terms } \\
\text { vork, education, etc., I } \\
\text { re it with my friends on } \\
\text { ial media }\end{array}$ & $\begin{array}{l}203 \\
(54.6 \%)\end{array}$ & 70 (18.8\%) & $99(26.6 \%)$ & 78.887 & $\mathrm{P}<0.001$ \\
\hline $\begin{array}{l}\text { soon as I have spare time, I } \\
\text { nd it on social media }\end{array}$ & $\begin{array}{l}281 \\
(75.5 \%)\end{array}$ & $48(12.9 \%)$ & $43(11.6 \%)$ & 298.274 & $\mathrm{P}<0.001$ \\
\hline $\begin{array}{l}\text { ny opinion social media can } \\
\text { p raise people's awareness } \\
\text { l knowledge }\end{array}$ & $\begin{array}{l}280 \\
(75.3 \%)\end{array}$ & $66(17.7 \%)$ & $26(7 \%)$ & 300.839 & $\mathrm{P}<0.001$ \\
\hline $\begin{array}{l}\text { iting social media is part of } \\
\text { schedule }\end{array}$ & $\begin{array}{l}286 \\
(76.9 \%)\end{array}$ & $40(10.8 \%)$ & 46 (12.4\%) & 317.613 & $\mathrm{P}<0.001$ \\
\hline $\begin{array}{l}\text { ¿ve no problem with my } \\
\text { ily using social media }\end{array}$ & $\begin{array}{l}299 \\
(80.4 \%)\end{array}$ & $49(13.2 \%)$ & $24(6.5 \%)$ & 372.984 & $\mathrm{P}<0.001$ \\
\hline $\begin{array}{l}\text { creating connections in } \\
\text { ial media, I consider } \\
\text { esty a must }\end{array}$ & $250(67.2 \%)$ & $91(24.5 \%)$ & $31(8.3 \%)$ & 206.565 & $\mathrm{P}<0.001$ \\
\hline $\begin{array}{l}\text { I social media, I usually } \\
\text { ggerate in introducing }\end{array}$ & $42(11.3 \%)$ & $57(15.3 \%)$ & $273(73.4 \%)$ & 269.468 & $P<0.001$ \\
\hline
\end{tabular}


ielf

eating social cohesion

Jng the people and

elerating the organization

Iseful political and social

vities is one of the positive

:cts of social media

ı social media, users are

; likely to declare their

sonality and identity

rectly and more likely to

nicknames and characters;

ause they do not have the essary confidence in this ironment to tell the truth i social media, like other

lia, biased individuals and ups carry out anti-religious paganda and attack on gious beliefs with determined goals and in cial ways

$r$ joining any social work, a person becomes Jlved in a certain type of ımunication culture, and hout a doubt, the degree to ch a person is affected by ; environment will not be olute zero. So each social work promotes its desired ntity 1e to the impossibility of ntifying the true identity of

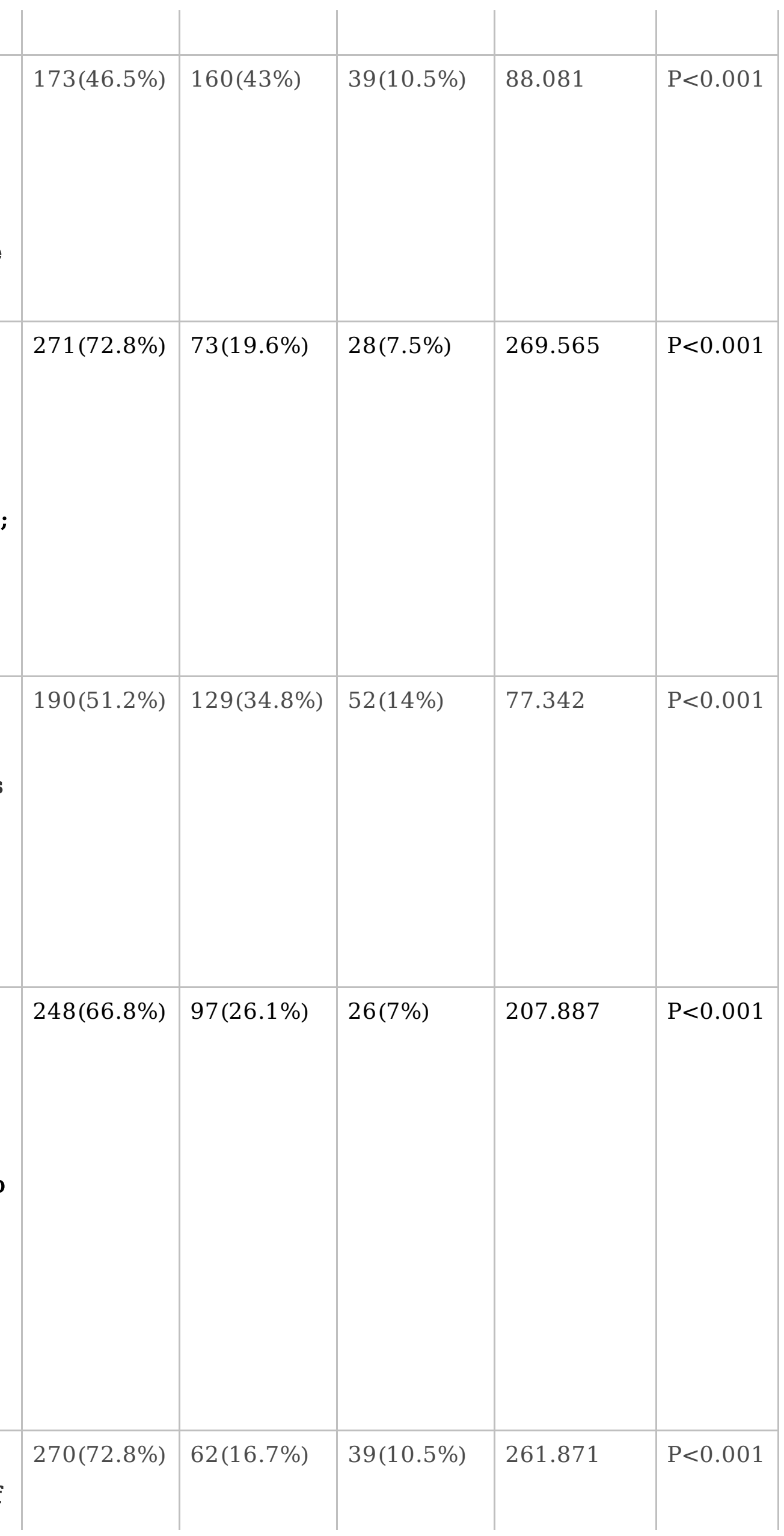


nbers and also the Iossibility of controlling the tent produced by users of ial media, one of the most ortant negative sequences of these works will be the formation ! rapid spread of rumors ! false news 1e more the connection of ividuals and members in social media, the more ly is the companionships l interactions and the ieness of mindsets and the erent and common rement will be cial media is an important rce of revenue through ertising le of the important abilities of social media is rovide an international form for the promotion I dissemination of religious, trinal, human and moral les

1e of the causes of inishing moral values and l-adherence to cultural $\mathrm{ms}$ is the facilitation of umunication with the osite sex through social lia

\begin{tabular}{|c|c|c|c|c|}
\hline $179(48.2 \%)$ & $149(40.2 \%)$ & $43(11.6 \%)$ & 82.566 & $\mathrm{P}<0.001$ \\
\hline $294(79.2 \%)$ & $70(18.9 \%)$ & 7(1.9\%) & 367.962 & $\mathrm{P}<0.001$ \\
\hline $20(5.4 \%)$ & $104(28 \%)$ & $247(66.6 \%)$ & 213.030 & $\mathrm{P}<0.001$ \\
\hline $84(22.6 \%)$ & $92(24.8 \%)$ & $195(52.6 \%)$ & 61.978 & $P<0.001$ \\
\hline
\end{tabular}




\section{Discussion}

In the present study, out of 380 students of different faculties of Kurdistan University of Medical Sciences who participated in the study, 373 (98.2\%) were on social media. This finding is consistent with a study conducted in 2018 by Kolan et al. in Ghana, which reported that $100 \%$ of the students were aware of social media platforms, and also a study conducted by Mousavi et al. in 2019 on 715 medical students in Sari which reported the total awareness of social media platforms among students to be $99.44 \%$. It is also consistent with several other studies with reports showing more than $85 \%$ popularity of social media in which a high prevalence of social media usage was reported (15-18)However, a study by Javadinia et al. In 2012 found that student membership on social media was 35\%, which contradicted our study (13). A comparison of the results of our study with other studies shows that students' use of social media is now widespread. This finding can be inferred from a study with similar findings; Modara meta-analysis, which is consisted of 30 studies conducted from 2006 to 2015 in Iran with sample size of 130531 and it emphasizes the high prevalence of Internet use (19).Therefore the reason for the discrepancy between Javadinia's study and our study may be the growth in Internet use. The findings of this study also show that the majority of 373 people who were on social media, spent about 3 hours on social media each day. The most popular social media platforms according to our study was Telegram, Instagram and WhatsApp, respectively. girls spent more time on social media than boys, and the results showed that $72.8 \%$ of students do not fully trust the media to express the truth.

The results of the present study suggest that the students on average spent 3 hours of their time on social media each day which supports Shaaban, Hanifeh et al., Upadahayay and Guragain's findings (20-22). Arab News in 2014 surprisingly reported that people of Saudi Arabia waste their time spending 8 hours on Internet each day, However, Larson et al. (2015), reported that $66.3 \%$ of people spend 0.5 to 1 hour on social media per day and few of them (32.2\%) spend more than one hour per day (23). It seems that the reason for this increase in use of social media is the advent of more easy-access smart devices, creating the need for people to use them for their daily and essential tasks, speeding up communication and entertainment, and also lack of facilities such as well-equipped gyms and recreational activities near the University campus and lack of interest in the field of study.

The results of the present study also showed that the most popular social media platforms among the students of Kurdistan University of Medical Sciences is Telegram, Instagram and WhatsApp, respectively. Ghorbani et al., in a study on Tabriz medical students, showed that the most popular social media platforms were Telegram and then Instagram, respectively (24) Mehdipour's study in 2018 on medical students in Zahedan showed that out of the average of 2 hours and 40 minutes that students spend on the Internet, Telegram plays the most prominent role (5). Babajani Wafsi also in her study stated that Telegram is the most popular social network in Iran(25).

These studies show that Telegram has a high capability for messaging and high educational potential in Iran. In a study conducted by Dashti et al., 79\% of social media use was related to Facebook and Twitter, followed by Instagram (26) which seems to contradict our findings. The reason for the popularity of Telegram is its user interface (possibility of making calls, creating channels, groups, etc.) and that it contains more features compared to other platforms.

Page 10/13 
The results also showed that female students use social media more than male students, while studies by Upadhayay and guragain, Dashti et al., As well as Anand et al., Showed that boys use social media more than girls $(22,26,27)$ Also Adiele and Olatokun's study on adults showed that the severity of Internet addiction in men is 3 to 1 compared to women (28). The study of Ghamari et al., on medical students in Arak considers being male to be one of the risk factors for Internet addiction (29). However Alamgir Khan et al., considers the amount of social media usage to be equal in both sexes (30) And Ahmer and Tanzil's study on Karachi medical students estimated that girls use social media more than boys, which is consistent with our study (31). It seems that restrictions on social, cultural, sports and other activities for girls, as well as special cultural circumstances in some areas and climates are the most important factors encouraging girls to spend more time on social media. The results showed that $72.8 \%$ of students do not fully trust the media to express the truth, while Forqani and Mohajeri in a study conducted in 2018 on the level the students trust social media in Tehran, The level of trust was a bit more than medium (32).

\section{Conclusion}

The results of the present study showed that $98 \%$ of students are on social media, and the average time spent on social media was 2.78. Given that social media has become an integral part of human life and students spend a lot of time on it, it is worthwhile to create a culture of proper use of social media. Students' use of social media should be in line with scientific attitude and educational purpose. Families and academic officials need to use appropriate educational programs and proper management to provide a suitable environment for students to use social media properly.

\section{Declarations}

\section{Ethics approval, accordance and consent to participate:}

This study was approved by the local ethics committee of Kurdistan University of Medical Sciences and all participants were satisfied to participate in our study.

\section{Consent for publication:}

Not applicable

\section{Availability of data and material:}

The data that support the findings of this study are Available on request from the corresponding author Pourya Bahrami. The data are not publicly available due to privacy/ethical restrictions.

\section{Competing interests:}

All authors have no competing interests.

\section{Funding:}

Kurdistan University of Medical Sciences 
Authors' contributions:

Not applicable.

\section{Acknowledgements:}

Not applicable.

\section{References}

1. Guan S-SA, Subrahmanyam KJCoiP. Youth Internet use: risks and opportunities. 2009;22(4):351-6.

2. Van Dijk JAJP. Digital divide research, achievements and shortcomings. 2006;34(4-5):221-35.

3. Lusk BJTpr. Digital natives and social media behavior: an overview. 2010;17(S1):3-7.

4. htpp://alexa.com/siteinfo.

5. Mehdipour YJJofm, care p. Medical students' life and virtual social networks a guide for educational managers and parents. 2019;8(8):2573.

6. service ksi. statistic on internet use 2016. https://kosiskr/eng/.

7. Villanti AC, Johnson AL, llakkuvan V, Jacobs MA, Graham AL, Rath JMJJomlr. Social media use and access to digital technology in US young adults in 2016. 2017;19(6):e196.

8. stats iwsmei. htpp://www.internetworldstats.com.

9. Kim SY, Kim M-S, Park B, Kim J-H, Choi HGJPO. The associations between internet use time and school performance among Korean adolescents differ according to the purpose of internet use. 2017;12(4):e0174878.

10. Poorolajal J, Ahmadpoor J, Mohammadi Y, Soltanian AR, Asghari SZ, Mazloumi EJHPP. Prevalence of problematic internet use disorder and associated risk factors and complications among Iranian university students: a national survey. 2019;9(3):207.

11. Basu S, Garg S, Singh MM, Kohli CJljopm. Addiction-like behavior associated with mobile phone usage among medical students in Delhi. 2018;40(5):446-51.

12. Hampton K, Wellman BJC, Community. Neighboring in Netville: How the Internet supports community and social capital in a wired suburb. 2003;2(4):277-311.

13. Javadinia SA, Erfanian M, Abedini M, Bijari BJIJoME. The effects of social networks on academic achievement of students, a study in Birjand University of Medical Sciences. 2012;12(8):598-606.

14. Dastani M, Keramati J, Poorfatemi A, Ekrami A. The reasons and motives of virtual social networks among students of Gonabad University of Medical Sciences. 2015.

15. Bernard KJ, Dzandza PE. Effect of social media on academic performance of students in Ghanaian Universities: A case study of University of Ghana, Legon. 2018.

16. Mousavi J, Shekofteh P, Amanolahi AJJoMUoMS. Frequency and Pattern of Social Network Use in Medical Students, Sari, Iran. 2019;29(172):146-52.

17. Mazhari SJA, health. The prevalence of problematic internet use and the related factors in medical students, Kerman, Iran. 2012;4(3-4):87. 
18. Mahmoudreza R, Zeynab Imaniyan M. Examining the impact of social networks on national identity. Soft Power. 2017;7(17):116-33.

19. Modara F, Rezaee-Nour J, Sayehmiri N, Maleki F, Aghakhani N, Sayehmiri K, et al. Prevalence of internet addiction in Iran: a systematic review and meta-analysis. 2017;9(4):243.

20. ShabanD HM. The role of Telegram social network on how to spend free time. afagh oloum ensani. 1398;25(0):1-18.

21. Mohamed HK, Sumitha EJDJoL, Technology I. Perception and Use of Social Networking Sites by the Students of Calicut University. 2011;31(4).

22. Upadhayay N, Guragain SJAime, practice. Internet use and its addiction level in medical students. 2017;8:641.

23. Taha MH, Shehzad K, Alamro AS, Wadi MJSQUMJ. Internet Use and Addiction Among Medical Students in Qassim University, Saudi Arabia. 2019;19(2):e142.

24. Gorbani M, Soheili A, Barghi IJTJUNMF. NURSING STUDENTS'PERSPECTIVE TOWARD THE ROLE OF VIRTUAL SOCIAL NETWORKS ON THEIR ACADEMIC ACHIEVEMENT IN TABRIZ UNIVERSITY OF MEDICAL SCIENCES. 2018;16(2):101-8.

25. Babajani-Vafsi S, Nouri JM, Ebadi A, Zolfaghari MJAiME, Practice. Factors Influencing The Participation Of Nurses In Knowledge-Sharing Within Mobile Instant Messaging Based Virtual Communities Of Practice: A Qualitative Content Analysis. 2019;10:897.

26. Naghi D, abbas a. The role of self- regulation, self-presentation and dark triad personality in predicting Social Networking Sites addiction in students of Ardabil University of Medical Sciences. Knowledge \& Research in Applied Psychology. 2018;19(72):11-21.

27. Anand N, Jain PA, Prabhu S, Thomas C, Bhat A, Prathyusha P, et al. Prevalence of excessive internet use and its association with psychological distress among university students in South India. 2018;27(1):131.

28. Salehi M, Khalili MN, Hojjat SK, Salehi M, Danesh AJIRCMJ. Prevalence of internet addiction and associated factors among medical students from Mashhad, Iran in 2013. 2014;16(5).

29. Ghamari F, Mohammadbeigi A, Mohammadsalehi N, Hashiani AAJljopm. Internet addiction and modeling its risk factors in medical students, Iran. 2011;33(2):158.

30. Khan MA, Shabbir F, Rajput TAJPjoms. Effect of gender and physical activity on internet addiction in medical students. 2017;33(1):191.

31. Ahmer Z, Tanzil SJPJoms. Internet addiction among social networking sites users: Emerging mental health concern among medical undergraduates of Karachi. 2018;34(6):1473.

32. Mohammad Mahdi F, Robabeh M. The Study on youth Trust Social Networks in Tehran. Journal of Culture Communication Studies. 2018;19(41):31-53. 